\title{
An Effective Teaching Method of the Course "Probability Theory and Mathematical Statistics" in Higher Education by Formative Evaluation
}

\author{
Shuai Liu \\ College of Computer Science \\ Inner Mongolia University \\ Hohhot, China \\ Weina Fu \\ College of Computer Science \\ Inner Mongolia University \\ Hohhot, China
}

\author{
Renyong Guo \\ College of Computer Science \\ Inner Mongolia University \\ Hohhot, China \\ Tieying Liu \\ College of Computer Science \\ Inner Mongolia University \\ Hohhot, China \\ * corresponding e-mail: cslty@imu.edu.cn
}

\begin{abstract}
Probability Theory and Mathematical Statistics" is a public mathematical elementary course for all science and engineering specialties in colleges and universities. It is because this course applies widely in many other professional courses of the specialties of science and engineering. But this course is full of theoretical knowledge and almost no practical experiment. It makes the students show little interest in this course. In this paper, we analyze disadvantage of classic educational method in course

"Probability Theory and Mathematical Statistics" at first. Then with practical nature of itself, we provide a novel evaluating method after a long time teaching practice in this course. We improve the classic evaluating method, which is examination on paper only, but bring the formative evaluation in the evaluating method. Finally, based on the new evaluating method, experiment results show advantage and effectiveness of this improved evaluating method.
\end{abstract}

Keywords- Probability Theory and Mathematical Statistics; Teaching Method; Higher Education; Formative Evaluation; Evaluating Method

\section{INTRODUCTION}

All manuscripts must be in English. These guidelines include complete descriptions of the fonts, spacing, and related information for producing your proceedings manuscripts. Please follow them and if you have any questions, direct them to the production editor in charge of your proceedings at Conference Publishing Services (CPS): Phone +1 (714) 821-8380 or Fax +1 (714) 761-1784.

This template provides authors with most of the formatting specifications needed for preparing electronic versions of their papers. All standard paper components have been specified for three reasons: (1) ease of use when formatting individual papers, (2) automatic compliance to electronic requirements that facilitate the concurrent or later production of electronic products, and (3) conformity of style throughout a conference proceedings. Margins, column widths, line spacing, and type styles are built-in; examples of the type styles are provided throughout this document and are identified in italic type, within parentheses, following the example. PLEASE DO NOT RE-ADJUST THESE MARGINS. Some components, such as multi-leveled equations, graphics, and tables are not prescribed, although the various table text styles are provided. The formatter will need to create these components, incorporating the applicable criteria that follow.

The course "Probability Theory and Mathematical Statistics", which is one of the most important course in all science and engineering specialties, contains two mainly subjects called "probability theory" and "mathematical statistics". The content of this course is shown in table 1 [1].

So, we find that this course is an active branch of applied mathematics with its own characteristics. On the one hand, the course has an important location with its special conceptions and methods; on the other hand, importance of the course reflects in its close relations with many other subjects. Today, the course is widely used into industry, agriculture, military, science and technology. Furthermore, theory and application of this course applies and combines to fundamental subjects and engineering. In this case, the teaching and studying of this case are important in higher education.

It is known that the course "Probability Theory and Mathematical Statistics" appears for years. Earlier, Hackney introduced and summarized this novel (for that year) subject to the academic world [2]. Meantime, 
TABLE II. CONTENTS OF "Probability ThEORY AND MATHEMATICAL STATistics"

\begin{tabular}{|c|c|c|}
\hline \multicolumn{3}{|c|}{ Probability Theory and Mathematical Statistics } \\
\hline \multirow{4}{*}{ Probability Theory } & table of contents & contents \\
\hline & Basic conception & $\begin{array}{l}\text { random trial; random event; frequency and } \\
\text { probability; Classical probability; conditional } \\
\text { probability; independence; etc. }\end{array}$ \\
\hline & random variable & $\begin{array}{l}\text { conception of random variable; discrete and } \\
\text { continuous random variable; functional } \\
\text { distribution of random variable; multivariate } \\
\text { random variable; Numerical characteristics of } \\
\text { random variables; etc. }\end{array}$ \\
\hline & Important theorems & law of large number; central limit theorem \\
\hline \multirow{5}{*}{ Mathematical Statistics } & statistic & random sample; sampling distribution; etc. \\
\hline & parameter estimation & $\begin{array}{c}\text { point estimation; interval estimation; } \\
\text { confidence interval; etc. }\end{array}$ \\
\hline & hypothesis testing & $\begin{array}{l}\text { sample mean; sample variance; fitting } \\
\text { inspection; etc. }\end{array}$ \\
\hline & Statistical analysis & $\begin{array}{l}\text { analysis of variance; regression analysis; } \\
\text { etc. }\end{array}$ \\
\hline & stochastic process & $\begin{array}{l}\text { Poisson process; Wiener process; Markov } \\
\text { process; etc. }\end{array}$ \\
\hline
\end{tabular}

Zolotarev presented some metrics of this subject [3]. Then, Pugachev published his writings about this subject [4]. Further, Shinzo and Prokhorov also published the proceedings of this subject [5]. Grigelionis et al also organized conference about this subject [6].

After year 2000, there were more publications in this subject, and many researchers focused on this subject. Valery et al published their writing for geometric aspects in this area [7]. Liptser summarized essentials in this subject [8]. Gatti also published his writing for engineering with knowledge in this subject [9].

Although there are many researches in this area, the mainly problem is still not being solved. The problem is the inadaptability of the studying and the teaching, especially in China. In this case, Chinese higher educators have researched in this problem with hard work for years. Cao et al presented some thoughts about application of concept maps to improve the teaching of this course [10]. Zhao used project-driven into the teaching method [11]. He believed project-driven is an effective improvement for this course. Liu et al also researched a way of whole curriculum reform for this course [12].

So in this paper, we proposed an effective teaching method of this course. This improvement mainly arises in the evaluating period. In order to drive the studying, we improve the classic evaluation, which is only on paper, by brought formative evaluation into this course. Experimental results show the effectiveness of this improvement.

The remainder of the paper is organized as follows. We present our formative evaluation in Section 2. Then, experimental results are presented and analyzed to validate the positiveness of ours in Section 3. Finally, Section 4 summarizes the whole paper.

\section{THE NOVEL FORMATIVE EVALUATION METHOD FOR THE COURSE "PROBABILITY THEORY AND MATHEMATICAL STATISTICS"}

Wherever Times is specified, Times Roman or Times New Roman may be used. If neither is available on your word processor, please use the font closest in appearance to Times. Avoid using bit-mapped fonts if possible True-Type 1 or Open Type fonts are preferred. Please embed symbol fonts, as well, for math, etc.

Fuchs found formative evaluation is an improvement in academic progress [13]. Perrenoud, Triantafillou and Flagg also study in the formative evaluation for different aspects [14-16]. All of these studies mean that formative evaluation is useful in higher education. So first, we have to find the negativeness of the classic evaluation.

\section{A. Negativeness of classic evaluation}

Classic evaluating method mainly evaluates students only by terminal examination on paper. So, the score of terminal examination holds the leading role in the evaluation of this course. In additional, the evaluation mainly examines the theoretical knowledge so that the students are also put their attention into the theoretical knowledge. Though the weight of formative grade exists, but it is quite smaller than the terminal grades. So this evaluating method is not effective because it is not effective when the students use knowledge into other subjects. Here, we conclude some negativeness of the classic evaluation.

1) Classic evaluation dislocates the purpose of evaluation

Purpose of evaluation must same to the purpose of education. First, the teaching of this course is for those students who do not belong to mathematical subjects. So the purpose for our teaching is to train students to use the knowledge of this course into other subjects of science and engineering. So, if we evaluate the students only or mainly by the terminal examination of theoretical knowledge, we will find that the students study the theoretical knowledge only. Objective element provides source power. So students we evaluate by classic evaluating method can only finish some tests on paper. They are considered as pseudo-talent because they cannot use their theoretical knowledge to their own subjects. This is dislocation purpose with higher education.

2) Evaluation form and method are single.

Classic evaluation has some properties, which are "more evaluations with no book, less evaluations with book"; "more evaluations with strict answer, less 
evaluations with reply open; "more theoretical evaluations, less formative evaluations of application"; "more objectivity evaluations with choices and checking questions, less subjectivity evaluations with comprehensive analysis and innovation". All these phenomena are negativeness to impel students to the result we expect. In fact, only the single evaluating method by one or two examinations on paper can not evaluate students overall for every course. The evaluation result is nonobjectivity and unilateral. It can not reflect true level mostly.

So, if we want students improve their study process as what we wanted, we must use more effective method of the evaluation. Of course, this objective must let students know at beginning of the lessons.

\section{B. The formative evaluation method}

The formative evaluation does not measure studying condition by use only a few examinations on paper. The purpose is to investigate the information of the studying level and to teach the ability of the use of this course in other subjects to students. So a better evaluating method is to hold the evaluating contents corresponding to the teaching content. In another word, the evaluating must biased toward what we want the student to study.

In this case, in our teaching, we divide evaluation into two parts. One is objective examination on paper (terminal examination), another is formative evaluation. In each part, we evaluate students in two sub-parts. The concrete evaluating method and score weight are shown below.

1) Objective evaluation

In objective evaluation, same to the classic method, we divide it into two parts. One is attendance of each student;
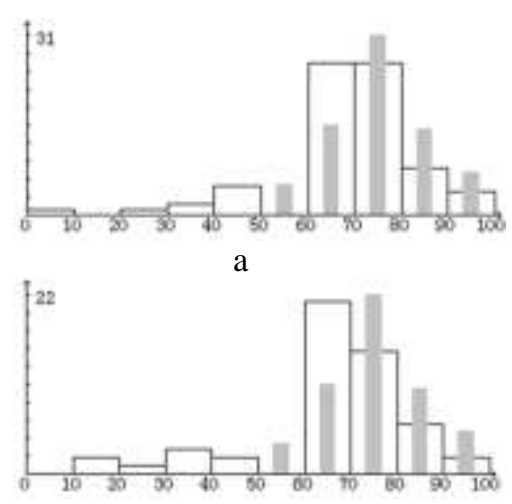

c
Another improvement is the content of the terminal examination questions. We abandon classic method and use a physical problem to evaluate the students. The students must know how to abstract the mathematical problem from the physical problem. Otherwise, they will not solve the problem.

\section{2) Formative evaluation}

The formative evaluation is another improvement. We also divide the formative evaluation into two parts. One is the phasing evaluation with every sub-contents of the course, which is called phasing evaluation. In this part, students must to solve some problems which can be solved by their current knowledge from the studying in the course. Every solution has its score, and the problems of all contents have relations. So students have their score by sum of all sub-contents. This method also makes the student finish all parts in the course. In our teaching, we give this part a weight of 15 percent. In this part, students know how to solve problems with the knowledge of this course.

The other wright of 15 percent is given to the midterm, which is between probability theory and mathematical statistics. This midterm summarize the total condition of students if they understand and use "probability theory" well.

\section{EXPERIMENTAL RESULTS AND ANALYSIS}

We use the novel formative evaluation during 2013-2014 spring term. Then, we compare the 2012-2013 spring term (with classic evaluation) and 2013-2014 spring term (with formative evaluation). In comparison, we can find the positiveness of the novel formative evaluations indeed.
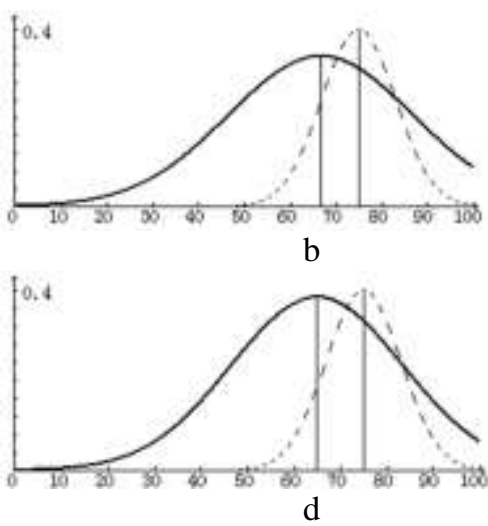

d

Figure 1. Scores and distributions for 2012-2013/ 2013-2014 spring term

the other is the terminal evaluation on paper.

In our teaching, we give attendance a small weight, 10 percent. This is because attendance is not equal to studying. So obviously, we can not use a large weight for the attendance. On the other hand, we must encourage those students who observe the discipline of university. So zero weight is also not suitable. Therefore, we give a weight of 10 percent for the attendance in total score.

In terminal evaluation, we give a weight of 60 percent, which is constructed by basic knowledge and applying ability. In classic evaluation, the weight of terminal evaluation is usually near weight of $80-90$ percent. But when we want to evaluate the applying ability of students, we use a smaller weight. We reduce it to 60 percent.
The number of students is 73 to study this course in 2012-2013 term, which is 52 during 2013-2014 term. The teacher of the two terms is same. It is admittedly we can assume that the students of two terms are all same with intelligence and other items.

First, in figure 1, we here present the distribution of scores for two terms (2012-2013 spring and 2013-2014 spring). The Fig .1a and Fig .1b are for scores of 2012-2013 spring term, and Fig .1c and Fig .1d are for scores of 2013-2014 spring term. Fig .1a and Fig .1c are histograms; Fig .1b and Fig .1d are curve graphs. In Fig .1, we find that the degrees of skewness with normal distribution (ds) of the two terms are 1.4006 (2012-2013) and 1.0557 (2013-2014). In additional, the degrees of 
skewness with distribution of expectance are 0.2695 (2012-2013) and 0.3477 (2013-2014). This means that the novel formative evaluation is effective in the classification of students, though the total scores are decrease. It is because the students are still not adapting the evaluation.

Then, the concrete distributions of scores are shown in tables 2-3. In these tables, we analyse that the new formative evaluating method motivates interest and excavates capacity of students. In these tables, we record the important indexes, which are means, highest scores (hs), lowest scores (ls), degrees of difficulty (dy), differentiation $(\mathrm{dn})$, relative-variance $(\mathrm{dr})$, and degrees of skewness with normal distribution (ds).

TABLE II. CONCRETE DISTRIBUTIONS OF SCORES

\begin{tabular}{c|c|c|c|c|c}
\hline Term & $\mathbf{0 - 6 0}$ & $\mathbf{6 0 - 7 0}$ & $\mathbf{7 0 - 8 0}$ & $\mathbf{8 0 - 9 0}$ & $\mathbf{9 0 - 1 0 0}$ \\
\hline $\mathbf{1 2 - 1 3}$ & 9 & 26 & 26 & 8 & 4 \\
\hline $\mathbf{1 3 - 1 4}$ & 8 & 21 & 15 & 6 & 2 \\
\hline
\end{tabular}

TABLE III. DISTRIBUTION OF SCORES IN STANDARD

\begin{tabular}{|c|c|c|c|c|c|c|c|}
\hline Term & mean & hs & Is & dy & dn & $\mathrm{dr}$ & ds \\
\hline $12-13$ & $6.7^{6}$ & 3 & 0 & $.33^{0}$ & $.33^{0}$ & $695^{0.2}$ & $006^{1.4}$ \\
\hline 13-14 & $5^{6}$ & $\begin{array}{ll}7 & 9 \\
7 & \end{array}$ & 2 & $.35^{0}$ & .4 & $477^{0.3}$ & $557^{1.0}$ \\
\hline
\end{tabular}

From table 2, we know that the studying effectiveness is not increasing obviously. But we find that the dy, dn of 13-14 are higher than 12-13, and ds of 13-14 are lower than 12-13. So we know that the distribution of scores are better in 13-14 than in 12-13. The increase of $\mathrm{dr}$ and decrease of mean are because the students are still not adapting the evaluation. This causes the general decrement for all students. It is the reason of the phenomenon in table 2 .

\section{CONCLUSION}

In this paper, we discuss the negativeness of classic evaluation of higher education in course "probability theory and mathematical statistics". Then, we experiment with the improved teaching method and analyze the different between the students which have been taught with the improved and with classic method. The experimental result shows the effectiveness of this improved teaching method.

\section{ACKNOWLEDGMENT}

The authors wish to thank the anonymous reviewers for their helpful comments in reviewing this paper.
This work was supported by foundation of promotion plan of western China (Specialty Construction of Management science and Engineering) [No. 140202010497].

\section{REFERENCES}

[1] Taboga M. Lectures on probability theory and mathematical statistics [M]. CreateSpace Independent Pub., 2012.

[2] Hackney O P. An Introduction to Probability Theory and Mathematical Statistics [J]. Technometrics, 1979, 21(3): 391-391.

[3] Zolotarev V M. Ideal metrics in the problems of probability theory and mathematical statistics [J]. Australian Journal of Statistics, 1979, 21(3): 193-208.

[4] Pugachev V S. Probability theory and mathematical statistics for engineers [M]. Elsevier, 1984.

[5] Shinzo W, Y.V. Prokhorov. Probability Theory and Mathematical Statistics with Applications [M]. Springer, 1988.

[6] B. Grigelionis, J. Kubilius, H. Pragarauskas, et al. Probability Theory and Mathematical Statistics: Proceedings of the Sixth Vilnius Conference (1993): Vilnius, Lithuania, 28 June-3 July, 1993[M]. VSP, 1994.

[7] Valery V. Buldygin, A.B. Kharazishvili. Geometric aspects of probability theory and mathematical statistics [M]. Springer, 2000.

[8] Liptser R S, Shiryaev A N. Essentials of Probability Theory and Mathematical Statistics [M] //Statistics of Random Processes. Springer Berlin Heidelberg, 2001: 11-37.

[9] Gatti P L. Probability theory and mathematical statistics for engineers [M]. CRC Press, 2004.

[10] CAO X, ZHENG J. Some Thoughts about Application of Concept Maps in Teaching Probability Theory and Mathematical Statistics [J]. Journal of Mathematics Education, 2007, 1: 011.

[11] Zhao X U. The Application of Project-Driven Teaching Method in Course of Probability Theory and Mathematical Statistics [C] //Higher Education Forum. 2012, 11: 009.

[12] Liu X, Feng Q, Zhang Y, et al. Research on Curriculum Reform Based on Probability Theory and Mathematical Statistics[M]//Informatics and Management Science I. Springer London, 2013: 481-485.

[13] Fuchs L S, Fuchs D, Hamlett C L, et al. Formative evaluation of academic progress: How much growth can we expect?[J]. School Psychology Review, 1993, 22: 27-27.

[14] Perrenoud P. "From formative evaluation to a controlled regulation of learning processes. Towards a wider conceptual field,' Assessment in Education, 1998, 5(1), pp. 85-102.

[15] Triantafillou E, Pomportsis A, Demetriadis S. "The design and the formative evaluation of an adaptive educational system based on cognitive styles," Computers \& Education, 2003, 41(1), pp 87-103.

[16] Flagg B N. "Formative evaluation for educational technologies," Routledge, 2013. 